\title{
Myocardial infarction: The model of coronary artery ligation in $\mathrm{Balb} / \mathrm{C}$ mice
}

Elisa Brosina de Leon ${ }^{1,2}$, Nadja Pinto Garcia ${ }^{2,3}$, Liziara Fraporti ${ }^{2,4}$, Gleicy Francisca Lima Almeida ${ }^{2}$, Leandro Eziquiel de Souza ${ }^{4,5}$, Diego Mendrot Taboas Figueroa ${ }^{4,5}$, José Fernando Marques Barcellos ${ }^{5,6}$, Luciana Botinelly Mendonça Fujimoto ${ }^{6}$, Maria Claudia Irigoyen ${ }^{4,5}$, Adriana Malheiro ${ }^{1,2,3,4}$

${ }^{1}$ Faculty of Physical Education and Physiotherapy, Federal University of Amazonas (UFAM), Manaus, Brazil.Programa Multi-Institucional de Pós-Graduação em Biotecnologia, Universidade Federal do Amazonas, Manaus, AM, Brasil.

Foundation of Hematology and Haemotherapy of Amazonas (FHEMOAM), Manaus, Brazil.

${ }^{3}$ Program of Post-graduation in Immunology, Federal University of Amazonas (UFAM), Brazil.

${ }^{4}$ Hypertension Unit, Heart Institute (InCOr), School of Medicine, University of São Paulo (USP), Brazil.

${ }^{5}$ Department of Morphology, Federal University of Amazonas (UFAM), Manaus, Brazil.

${ }^{6}$ Department of Pathology and Legal Medicine, Federal University of Amazonas (UFAM), Manaus, Brazil.

\begin{abstract}
Background: The experimental model of myocardial infarction after coronary artery ligation in rodents has been the model of heart failure more widely used in cardiology. This model has several characteristics that must be considered during the development of experimental research.

Objective: To evaluate the effects of model of heart failure in mice undergoing surgery for left coronary artery ligation on the functional and morphological measurements, comparing them to animals that underwent surgery without artery obstruction.

Methods: Surgical ligation of the left coronary artery was performed in female mice isogenic Balb/C (MI + PBS group). Control animals underwent the same surgical procedures, but without coronary artery ligation (Control group). After 30 days was performed functional capacity evaluation by stress test, echocardiography and tissue collection.

Results: After 30 days of induction of myocardial infarction, all animals in the infarcted group showed abnormal ventricular contractile segmental result, reflected by the perimeter infarction (30\%) and pathologic analysis which process shown hyalinization in $45 \%$ of animals. Important inflammatory infiltrates process was identified in lung pathologic analysis, 5 control mice and 5 IM + PBS animals.
\end{abstract}

Conclusion: Our results allow us to conclude that the model of infarction caused by ligation of the left coronary artery is a good experimental model, demonstrated by echocardiographic assessments, which contribute to the deepening pathophysiological and therapeutic syndrome of heart failure, despite its peculiarities.

\section{Introduction}

The experimental model of myocardial infarction after coronary artery ligation in rodents has been the animal model of cardiac insufficiency most widely used in research in experimental cardiology [1], which contributes to the pathophysiology and therapeutical analysis of this syndrome [2]. The model was first described by Heimburger in 1946 [3] in small animals and was progressively modified by Johsn \& Olson in 1954 [4]. This procedure consists of opening the thorax after thoracotomy to the left between the third and fourth intercostal space, with the animal intubated and mechanically ventilated. The pericardium is carefully opened for exposing the heart, which is partially immobilized, with its apex gently pressed between the thumb and forefinger. The left coronary artery is obstructed by the passage of suture wire. The heart is repositioned, the thorax closed by ribs reapproximation and sutured skin [5].

Partial occlusion of the left coronary artery leads to myocardial ischemia, which initiates an inflammatory reaction, activating repair mechanisms that ultimately results in cicatricial scarring [6] and, consequently, heart failure $[1,7]$, as shown in the figure 1 . The method described above has several advantages. Firstly, we can used modified animals for specific protocols and at a lower cost than in larger animals. Secondly, the surgery is extremely fast, with a duration ranging from 2 to 5 minutes [8].

This model of induction of HF, similarly to mice and mice [9], leads to hemodynamic changes similar to those presented in humans, such as decreased heart rate, mean arterial pressure [10-11], and increased LV end-diastolic pressure [11-13]. In addition to the central alterations, the model results in systemic changes in neurohormonal regulation [12], changes in peripheral capillarization [14-15] and other peripheral alterations in relation to oxidative stress and metabolism [16].

Correspondence to: Elisa Brosina de Leon, Faculty of Physical Education and Physiotherapy Programa Multi-Institucional de Pós-Graduação em Biotecnologia, Federal University of Amazonas (UFAM), Brazil. Universidade Federal do Amazonas, Manaus, AM, Brasil, E-mail: elisadleon@yahoo.com.br.

Key words: experimental model, heart failure, mice, coronary occlusion

Received: August 16, 2017; Accepted: September 20, 2017; Published: September 23, 2017 
Despite being a widely used model for the study of pathophysiological changes due to coronary occlusion, the model presents several peculiar characteristics that may hinder its handling. Thus, the objective of this study was to evaluate the effects of the cardiac failure model in mice submitted to left coronary artery ligation surgery on the central and functional tissue morphological characteristics, comparing them to the animals submitted to the surgical procedure without obstruction of the artery.

\section{Methods}

\section{Animals}

The present study was approved by the Commission of Ethics in Animal Experimentation of the Federal University of Amazonas (CEEA-UFAM), under protocol no017/2010 in a meeting held on $05 / 07 / 2010$, because it was in accordance with ethical principles in animal experimentation, Adopted by the Brazilian College of Animal Experimentation (Cobea) (http://www.cobea.org.br).

In this study, mice, BALB/c females, 4-6 weeks of age, were from the (UNESP). These mice were kept in laboratory-specific enclosures with ambient insulation, automatic light control (light and dark cycles of 12 hours), temperature $\left(22^{\circ}\right)$ and constant humidity fed with standard feed and water ad libitum.

Induction of acute myocardial infarction through the ligature model of the left coronary artery

The animals were initially anesthetized by inhalation using sevoflurane anesthetic (Baxter Ind. \& Co., Deerfield, USA) with continuous flow of oxygen mixture, intubated and artificially ventilated (Rodent Ventilator model 683 - Harvard, Massachusetts, USA). The technique used to induce infarction was the ligature model of the left coronary artery (4-5). The temperature of the animal was between $36.8^{\circ}$ and $37^{\circ} \mathrm{C}$ in a warm surgical bed (Insight Ltda, Ribeirão Preto, Brazil) during the surgical procedure. Animals Control Group: Control group mice done to the same surgical procedure, but without coronary artery ligation.

The evolution of the body weight of all animals was monitored weekly, in a semi-analytical balance (SF-400, Marca Electronic, SP, Brazil) during the experiment period until the conclusion of the experiment.

\section{Experimental draw}

After the surgical procedure, the animals belong into the following experimental groups: false operated (Control, $\mathrm{n}=10$ ) and myocardial infarction, which was administered $0.9 \%$ phosphate-saline buffer solution for volume maintenance (IM + PBS, $\mathrm{N}=11$ ). Control animals did to all surgical procedures, except coronary artery ligation. We observed all animals for four weeks.

\section{Functional capacity assessment}

The physical exertion test was performed after two days of adaptation of the animal in a treadmill, through stepwise progressive test, until exhaustion of the animal [17], with initial velocity of 11 $\mathrm{m} / \mathrm{s}$, without inclination, after 28 days of induction Of the infarction. Every three minutes, the velocity increased by $5 \mathrm{~m} / \mathrm{s}$, until the animal exhaustion, that is, the test ended when the animal could not maintain the running pattern. The variables evaluated: the final velocity $(\mathrm{m} / \mathrm{s})$ and the total distance traveled $(\mathrm{m})$ per animal during the test.

\section{Echocardiographic examination}

After a period of 30 days, the animals were anesthetized and ventilated, as previously described, for echocardiographic examination, as described by Farahmand et al. [18]. After tricotomy of the anterior thoracic region, the animals were placed in dorsal decubitus in a heated surgical bed for the appropriate positioning of the transducer in the left hemithorax of the animal. The GE ${ }^{\bullet}$ VIVID 5 equipment (Highland Park Dr. Bloomfield, USA) with an $8 \mathrm{MHz}$ transducer was used for this examination. The infarct area was estimated by determining the internal perimeter of the infarcted region in relation to the total perimeter of the heart [19]. At each echocardiographic exam, a total of three measurements were collected, and the mean and standard deviation were subsequently calculated. Through this analysis, the total perimeter of the left ventricle and the perimeter of cicatricial scarring were measured in the infarcted groups, allowing the calculation of the percentage of infarction.

\section{Collection of fabrics}

After blood collection, the animals were euthanized by cervical dislocation. Next, heart, lung and liver were collected. The hearts were removed and dissected, separating the atria and the left and right ventricles, the ventricular septum being considered integral to the left ventricle. After weighing the analytical balance (Adventurer, model Ohaus, Col. Lindavista, Mexico), the left ventricles and lungs were fixed in $10 \%$ formalin solution, used for histopathological analysis. The left tibia was removed and weighed for normalization of the weights of the heart, ventricles, lung and liver. The presence of cardiac hypertrophy was determined using the weight of the heart and the weight of each left and right ventricle, isolated for each animal. The presence of pulmonary and hepatic congestion was determined using the weight of each organ (left lung and liver) of each animal. To analyze these data, the weight of each tissue was corrected by the animal's tibia weight (mg), and the result was presented in $\mathrm{mg} / \mathrm{mg}$ [20].

\section{Anatomopathological analysis}

The samples were preserved in $10 \%$ formalin and included in paraffin blocks for cutting and staining. The 5-micron thick sections were obtained by microtome model CUT 4055 (SLEE Technik GmbH, Mainz, Germany), and placed on a previously identified glass slide. After obtaining all the slides, they were placed in an oven for about 30 minutes for deparaffinization of the tissues and subsequent staining of the same. The histological sections were stained by the HematoxylinEosin technique [21], to evaluate the cytoarchitectural findings. When necessary, auxiliary staining, such as Gomori's trichrome [22], was performed to better visualize collagen fibers. The histopathological test was performed in the simple-blind model, aiming to evaluate the following parameters: left ventricle and right ventricle, (1) fiber disorganization, (2) hyalinization, (3) calcification, (4) endocardial thickening, (7) Thinning, (6) inflammatory infiltrate, and (6) angiogenesis; In the lung, (1) alveolar distention, (2) congestion and (3) inflammatory infiltrate.

\section{Statistical analysis}

The results obtained were stored in the Excel $^{\oplus} 2007$ program for Windows $7^{\oplus}$. GraphPadPrism ${ }^{\circ}$ version 5 . The numerical results were expressed as mean \pm SEM. For the analysis of the variables obtained, we used an unpaired Student t-test. Pearson's chi-square test ( $\chi 2$ ) was used for correlation analysis. The level of significance used in all analyzes was less than $5 \%(\mathrm{p}<0.05)$. 


\section{Results}

\section{Mortality}

In total, 24 animals were used in the study, of which 12 were submitted to the surgery of induction of infarction with obstruction of the left coronary artery and 12 mice were submitted to the control surgery. The perioperative mortality rate, which includes $24 \mathrm{~h}$ after the procedure was higher in the Control group ( 2 animals) than in the IM + PBS group (1 animal). No death involved cardiac rupture in either group.

\section{General characteristics of experimental groups}

The studied group was considered homogeneous since the mice presented no significant difference in body weight at the beginning of the study. Similarly, body weight measured at the end of the study did not differ between groups, as shown in table 1 . The weight of the hearts as well as the left ventricle weight increased $18 \%$ and $20 \%$, respectively, when compared to the group Control, and these signs are compatible with post-infarction cardiomegaly. The corrected weight of the lungs and liver was not different in any of the evaluated groups.

\section{Function of the left ventricle}

As described previously, ligation of the left coronary artery is an efficient procedure in the induction of myocardial infarction. In the present study, the perimeter of the left ventricular infarction of the mice was evaluated using the echocardiographic exam. We observed in Figure 2 that, after 30 days of infarction induction, all animals in the infarcted group that received PBS (IM + PBS) presented contractile segmental changes of the ventricle in an anatomopathological study related to the findings of dyskinesia and akinesia. No animals in the control group presented left ventricular echocardiographic alterations suggestive of myocardial infarction. The infarct perimeter in the IM + PBS group was $\sim 30 \%$, demonstrating the efficacy of the experimental procedure.

\section{Evaluation of functional capacity}

The stress test was performed with the purpose of verifying the resistance to exercise induced by the experimental model in progressive test until the exhaustion of the mouse. The results obtained in the exercise resistance test showed no significant difference in the total distance walked (Figure 3 ) and final velocity reached (Figure 4 ) by the control group, when compared to the $\mathrm{IM}+\mathrm{PBS}$ group (Control = $510.3 \mathrm{~m} \pm 137.3, \mathrm{IM}+\mathrm{PBS}=572.9 \mathrm{~m} \pm 206.0)$ and $($ Control $=0.66 \mathrm{~m} / \mathrm{s} \pm$ $0.06, \mathrm{IM}+\mathrm{PBS}=0.69 \mathrm{~m} / \mathrm{s} \pm 0.09)$, respectively.

The correlation analysis between the functional test and the echocardiographic data in animals submitted to surgical procedure with coronary artery obstruction (IM + PBS group) showed that the

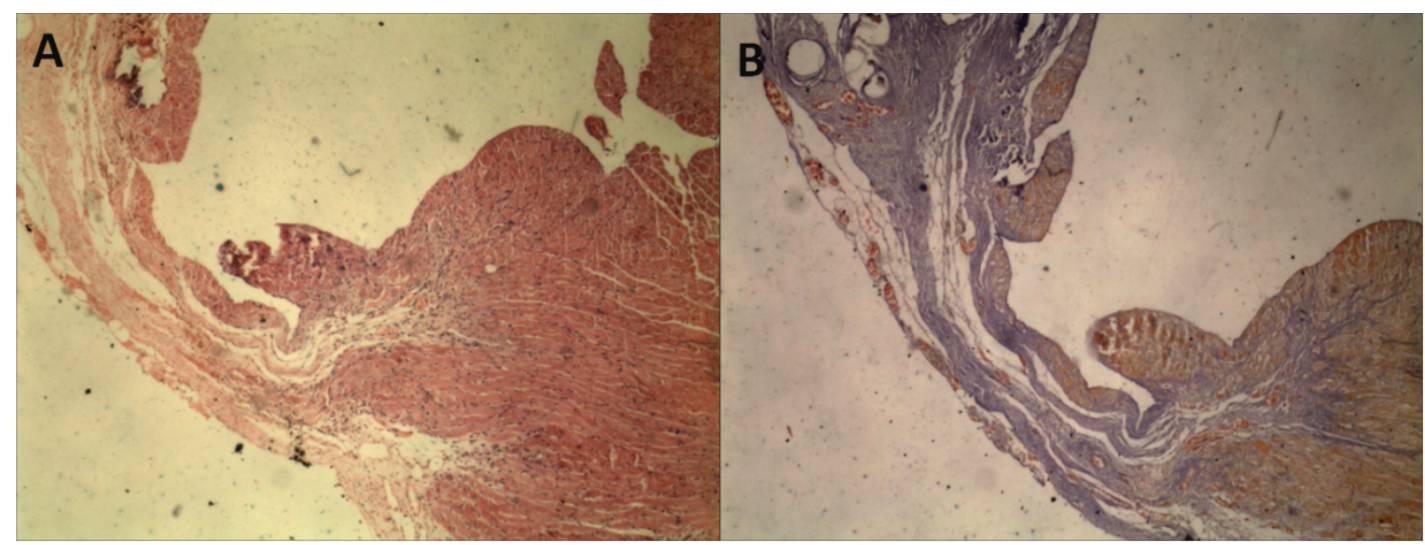

Figure 1. Left ventricular myocardial section of an infarcted animal, demonstrating the use of the Hematoxylin and Eosin (A) technique and Gomory's (B) trichromic staining technique. The image represents myocardial thinning area with replacement by collagen (blue) forming cicatricial scarring following myocardial infarction.

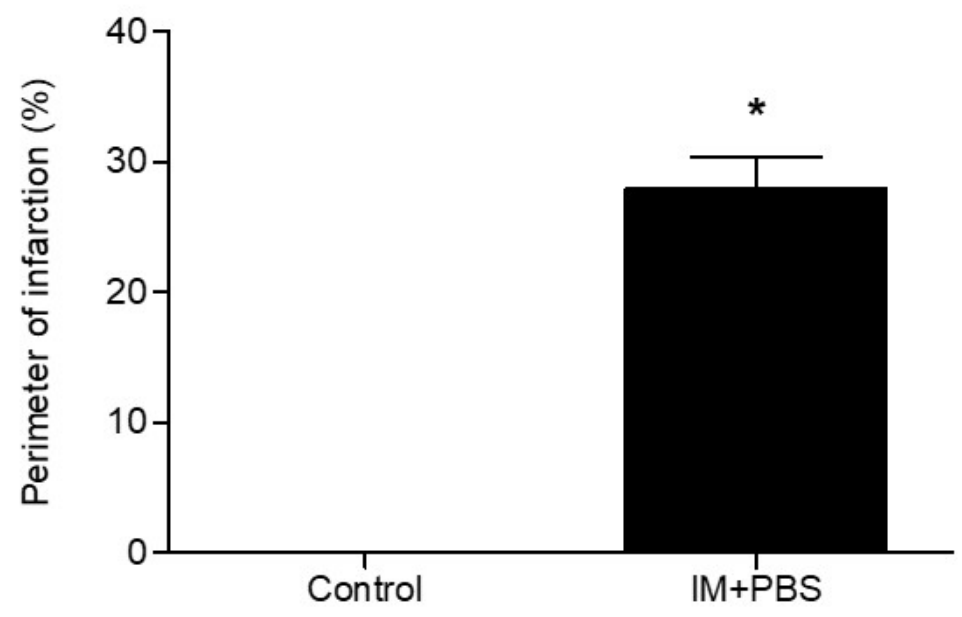

Figure 2. Perimeter of infarction of the left ventricle. Sham groups and HF (infarction $+0.9 \%$ phosphate-saline buffer solution). The results are presented as a percentage of the perimeter of infarct / total left ventricular perimeter measured in the echocardiographic analysis, after a period of 4 weeks of induction of the experimental infarction. * Statistical significant difference between the groups HF and Sham $(\mathrm{p}<0.0001)$ by t-Student test. 

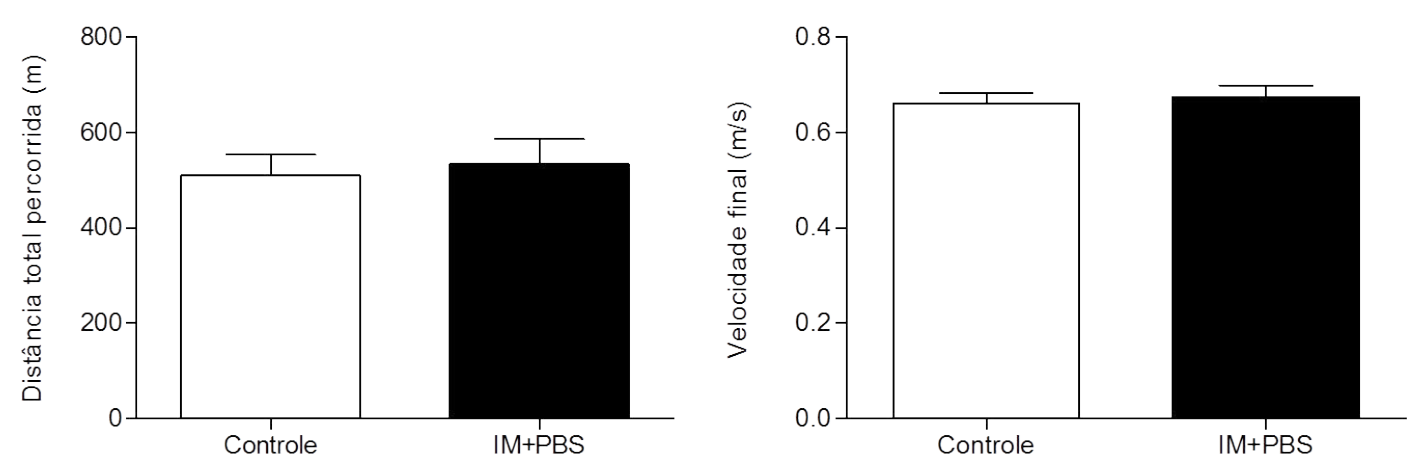

Figure 3. Correlation between total distance traveled (A) and final velocity reached (B) obtained in progressive test until exhaustion and perimeter of infarction observed in echocardiographic evaluation in mice submitted to surgery of induction of myocardial infarction after 4 weeks (IM + PBS). Statistical analysis using Pearson's chi-square test ( $\chi 2$ ).
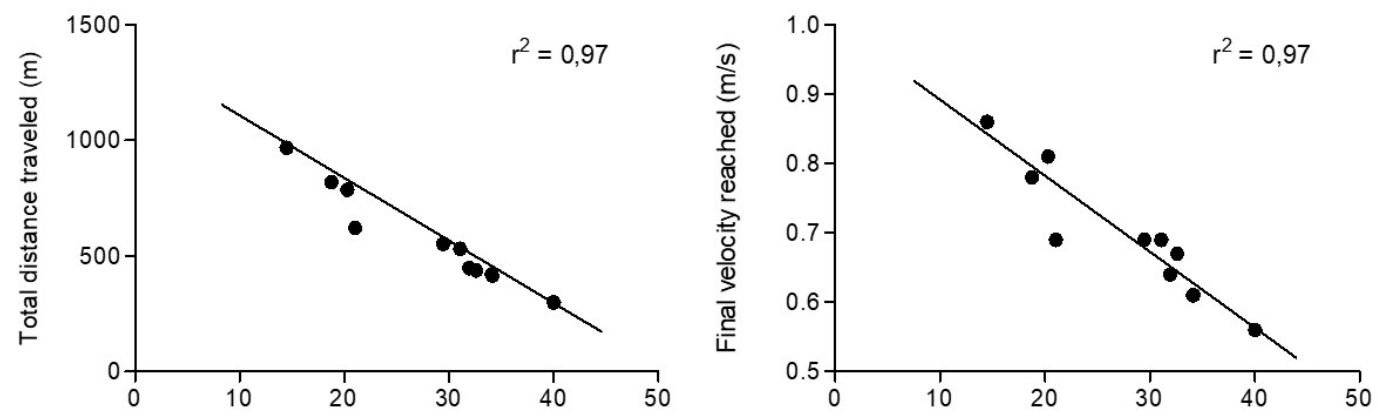

Figure 4. Results of morphological findings of the left ventricle (LV) and right ventricle (RV) and lung in the Sham animals after 30 days of experimentation. The data referring to the histopathological findings are presented from the frequency of appearance of each event, with each line representing one mouse from each group.

Table 1. Morphologic statements. * Significant difference between the Sham group (t-Student test)

\begin{tabular}{|l|c|c|c|}
\hline \multicolumn{1}{|c|}{ Groups } & $\begin{array}{c}\text { Control } \\
(\mathrm{n}=10)\end{array}$ & $\begin{array}{c}\text { IM+PBS } \\
(\mathrm{n}=11)\end{array}$ & $p$ \\
\hline Initial body weight $(\mathrm{g})$ & $21,44 \pm 2,35$ & $20,83 \pm 1,32$ & 0,28 \\
\hline Final Body $(\mathrm{g})$ & $23,9 \pm 1,91$ & $23,91 \pm 1,3$ & 0,98 \\
\hline Heart $(\mathrm{mg} / \mathrm{mg})$ & $2,28 \pm 0,28$ & $2,71 \pm 0,51^{*}$ & 0,01 \\
\hline Left ventricle (mg / mg) & $1,58 \pm 0,24$ & $1,91 \pm 0,34^{*}$ & 0,01 \\
\hline Right ventricle (mg/mg) & $0,38 \pm 0,06$ & $0,46 \pm 0,15$ & 0,07 \\
\hline Lung (mg/mg) & $1,5 \pm 0,24$ & $1,79 \pm 1,08$ & 0,19 \\
\hline Liver $(\mathrm{mg} / \mathrm{mg})$ & $22,1 \pm 3,51$ & $22,94 \pm 4,24$ & 0,2 \\
\hline
\end{tabular}

higher the cardiac dysfunction determined by the infarct perimeter, the greater the intolerance of the mice in the test $(\mathrm{P}<0.001)$, both in the evaluation of the total distance traveled (Figure 5) and in the final velocity achieved (Figure 6).

\section{Anatomopathological analysis}

The results of morphological findings observed in the left and right ventricles and lungs, after 30 days of experimentation, are presented in Figures 7 and 8 . The data for the group of control and IM + PBS mice are presented below: in the left ventricle of the group Control, according to figure 7 and 9A, no disorganization of the muscular fibers was observed, and the striated cardiac muscle cells were organized, containing one or two nuclei and branching cytoplasm, giving a continuous network aspect. Figure 8 shows the presence of this finding in $36 \%$ of the infarcted animals. The mice in the control group had no evidence of a left ventricular hyalinization process, however, $45 \%$ of the IM + PBS mice presented this event. In a controversial way, 1 animal in the control group showed presence of calcification in the left ventricle after the control surgery and 2 animals presented in the IM
+ PBS group. No myocardial thickening or thinning of the wall was observed in the control group, which was observed in 36\% and $45 \%$ of the IM + PBS animals, respectively. Histological sections of the left ventricle of the animals of the control group demonstrated the presence of inflammatory infiltrate in 1 mouse of this group and 2 animals of the IM + PBS group. No angiogenesis was observed in the control group, which was reported in 1 animal from the IM + PBS group.

Tissue analysis of the right ventricle showed the presence of cardiac muscle fibers in the usual arrangement, partially coated with no particular endocardium, interspersed with blood vessels, in the control group, but 1 mouse presented alteration in the IM + PBS group. No mouse in the control group presented right ventricular hyalinization, and 1 animal presented in the IM + PBS group. Histological findings related to calcification, endocardial thickening and thinning were found in the following proportions: Control group: $20 \%, 10 \%$ and $10 \%$; And IM + PBS group, $18 \%, 9 \%$ and $27 \%$, respectively. No alterations of normality were observed regarding the presence of inflammatory infiltrate in the RV in any mouse, as well as angiogenesis.

Histological sections obtained from the lungs of mice of the Control group demonstrated preserved lobular histoarquitetura, recognizing terminal bronchiole, respiratory bronchiole and adjacent alveolar tissue. Acidopulmonary analysis revealed alveolar hyperdistension in 1 mouse of this group. Event not reported in IM + PBS group. The presence of moderate alveolar congestion in 2 animals of the control group and in $45 \%$ of IM + PBS. We identified an important inflammatory infiltration process in 5 control mice and 5 IM + PBS animals.

\section{Discussion}

The present study demonstrated that myocardial infarction induction surgery after ligation of the left coronary artery involves 


\section{Control}

LV $\mathrm{RD}$ Lung
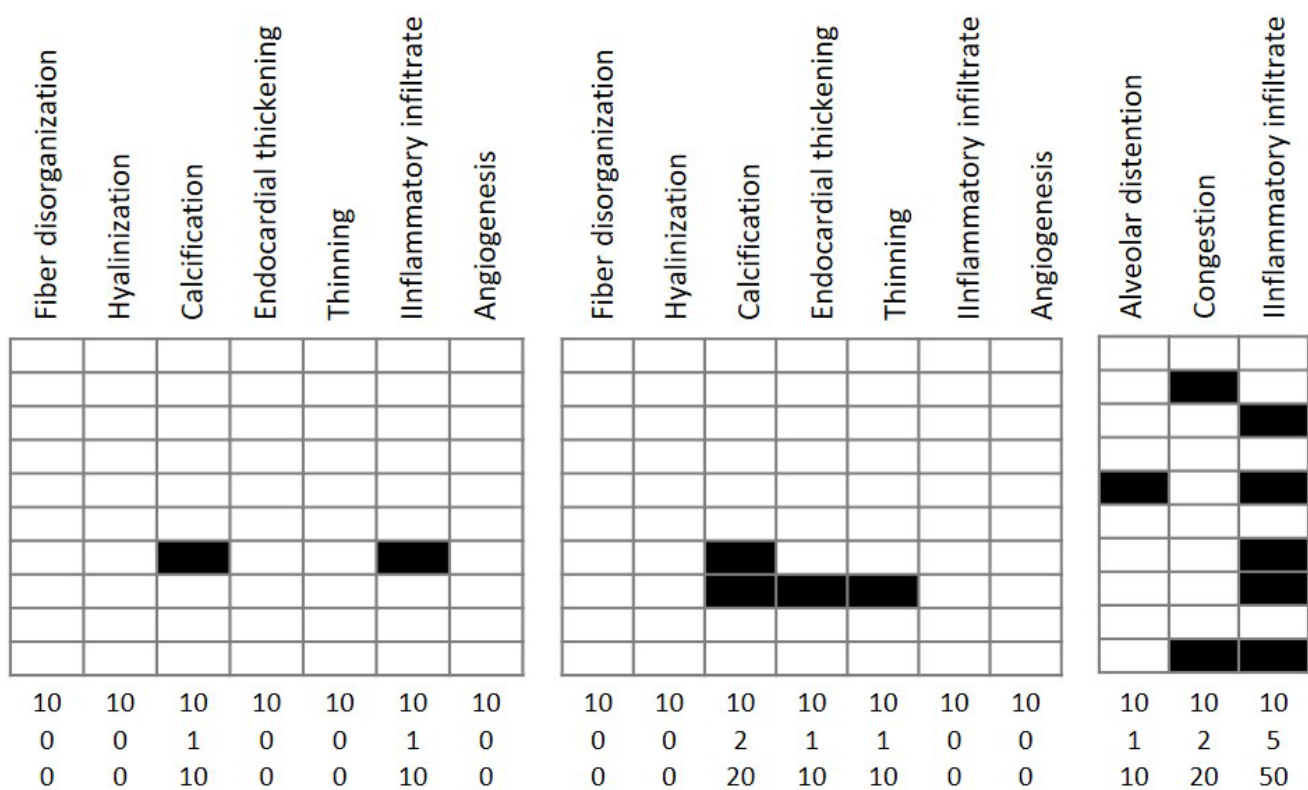

Presence $(n)$

$\%$

Figure 5. Results of morphological findings of left ventricular (LV) and right ventricle (RV) and lung in animals of HF group after 30 days of experimentation. The data referring to the histopathological findings are presented from the frequency of appearance of each event, with each line representing one mouse from each group.

\section{IM+PBS}

LV

$\mathrm{RD}$

Lung

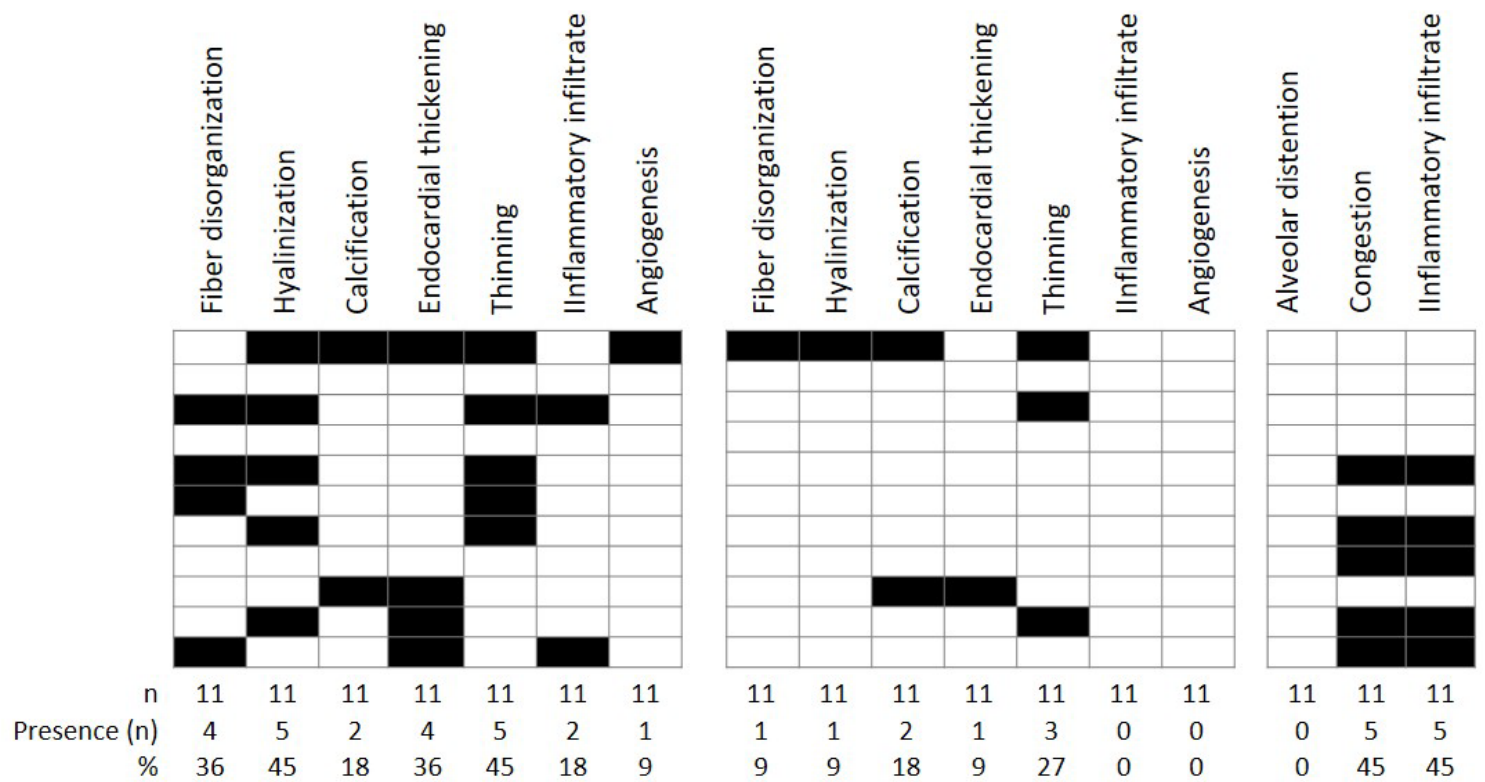

Figure 6. Morphological aspect of the left and right ventricles of the Sham and HFmice after 30 days of myocardial infarction induction surgery. Morphological aspect of normal alignment of cardiac fibers in animals Sham in (A) left ventricles and (B) right ventricle; (C) and (D): left ventricle of the animals after infarction induction demonstrating area of cardiac fiber disorganization, with evident interposition of collagen. (E) and (F): right ventricle demonstrating presence of calcification (*) Hyalinization event. Arrow indicates foci of calcification (HE, 40x). 


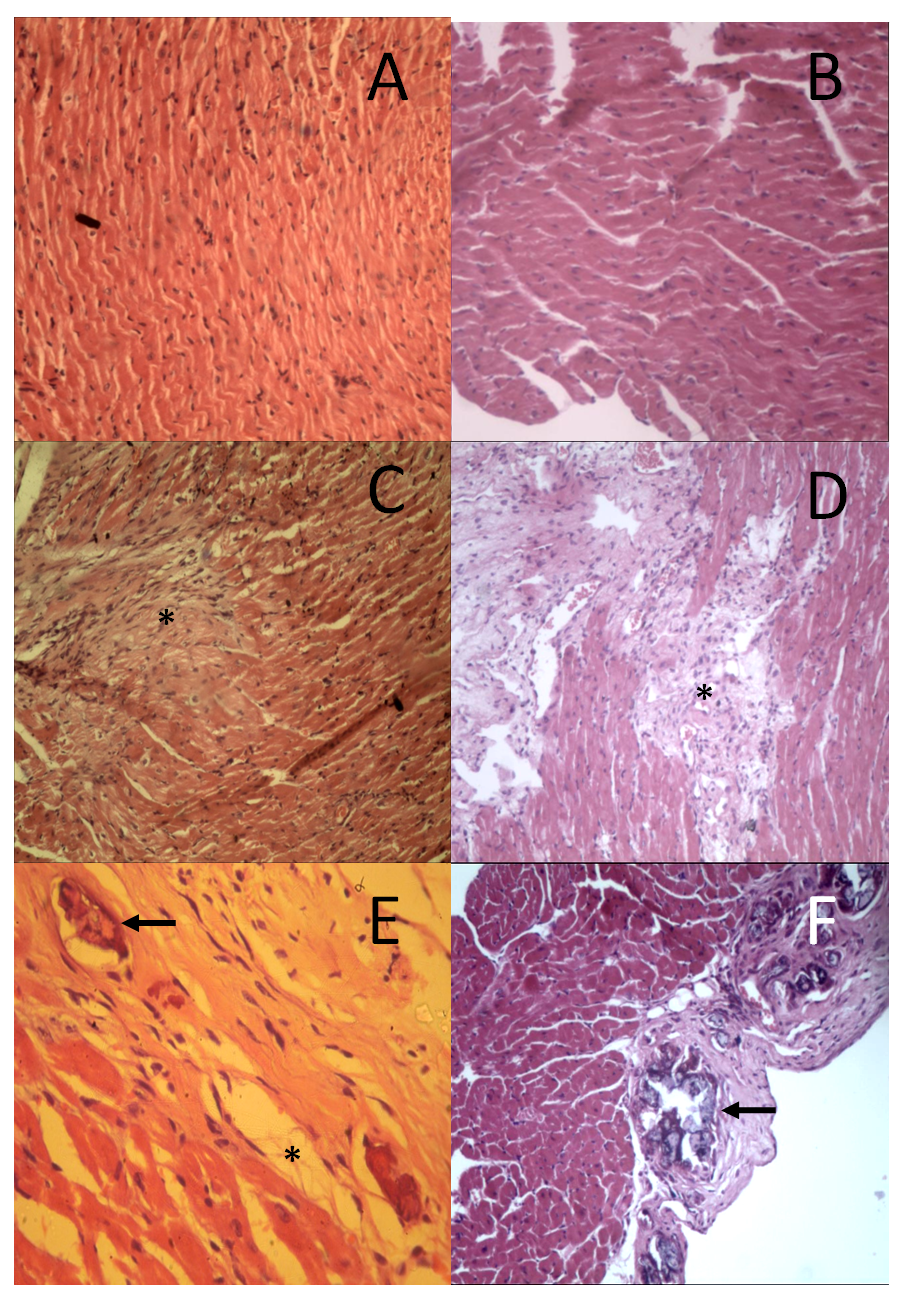

Figure 7. Morphological aspect of the lungs of Sham group mice after 30 days of myocardial infarction induction surgery. (A) representative image of the lung tissue presenting preserved bronchial structures and absence of congestion. (B) Parenchyma showing distention of alveolar spaces and $(*)$ presence of perivascular and peribronchial cell accumulation areas interpreted as an inflammatory infiltrate.

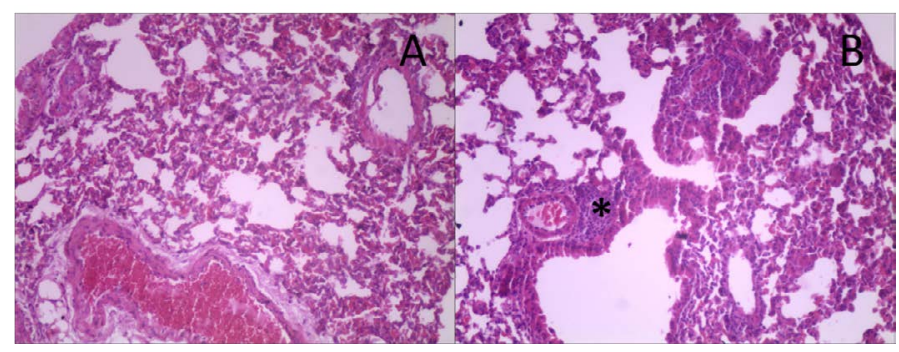

Figure 8. Morphological aspect of the lungs of control group mice after 30 days of myocardial infarction induction surgery. (A) representative image of the lung tissue presenting preserved bronchial structures and absence of congestion. (B) Parenchyma showing distention of alveolar spaces and $(*)$ presence of perivascular and peribronchial cell accumulation areas interpreted as an inflammatory infiltrate.

pathophysiological changes that correspond to the characterization of the syndrome in humans, allowing the use of this test as a resource for the best knowledge in experimental cardiology. However, it should be pointed out that control animals, which undergo the experimental procedure without obstruction of the artery, also present central and peripheral alterations due to the manipulation, which may, eventually, compromise the observed final results.
Echocardiographic data demonstrated the formation of cicatricial scarring after the experimental surgery, which was visualized in all mice submitted to the infarction, which was approximately $30 \%$, similarly to what was previously observed by other authors [23]. This result corroborates the findings regarding the increase in the weight of the heart and ventricles in mice of the IM + PBS group, which indicate myocardial hypertrophy. These data are in agreement with those found by de Leon et. Al (2011) where cardiac hypertrophy was observed after 30 days in rats submitted to experimental myocardial infarction associated with pulmonary congestion and hepatic congestion, clinical signs of heart failure [11]. However, in our study, we did not observe a significant difference between the groups in relation to the weights of the lung and liver organs. Thus, we chose to classify the IM group as animals with ventricular dysfunction after MI and not with HF, according to Lopes et al. (2009) [24].

Data from the literature demonstrate that there are two important factors that should be considered in the coronary artery ligature infarction model: high mortality in the first 24 hours following coronary occlusion and expressive diversity of the sizes of the infarcts obtained [2]. The diversity of infarct perimeters is reflected in the results presented in our study, in which we observed a variability between 15 and $40 \%$ of the rate between infarct perimeter and total left ventricular perimeter. Another fundamental characteristic of this model is that the functional alterations are closely related to the infarct size. Studies have shown $[8,25]$ that animals with infarc- tions below $30 \%$ did not present hemodynamic abnormalities. Animals with moderate infarcts (31-46\%) presented normal baseline hemodynamic values, but reduced capacity to generate pressure. On the other hand, animals with large infarcts (> $46 \%$ ) had heart failure, with high filling pressures and reduced cardiac output. Similar data were demonstrated in the present study in which a negative correlation was observed between the values measured in the exercise test - total distance traveled and final velocity achieved and the perimeter of infarction in the animals that were submitted to the infarct operation produced by ligature of the artery, According to figures 5 and 6 . The histopathological analysis of the left ventricle of the mice of the IM + PBS group showed a high presence of lesional tissue events produced by the experimental surgery, including the presence of hyalinization, cicatricial scarring due to cell death and the presence of calcification. This finding suggests a possible exacerbation of the immune response to the damaging event, leading to impairment of the heart pump's ability to function. Studies demonstrate $[26,27]$ a correlation between cardiac dysfunction indexes and functional tests, corroborating those found in our study.

Controversial result was visualized in the left ventricle of control mice, and 1 animal presented a calcification process due to surgical manipulation. These findings were also reported in the right ventricle, which presented alterations related to calcification ( 2 animals), endocardial thickening and thinning of the wall in this group (control group).

The experimental model in mice also allows right ventricular evaluation, since one of the main features of myocardial infarction is related to the fact that cell death triggers an adaptive process in non-infarcted tissue in the adjacent and distant regions of the scar [28]. In the right ventricle, hypertrophy correlated with elevations in left ventricular end-diastolic pressure and right ventricular systolic pressure [25,29] may also occur, up to $30 \%$ [30]. In our study, we observed alterations in $9 \%$ of the mice related to endocardial thickening and $27 \%$ related to thinning of the right ventricular wall. Another aspect that should be considered is that, in animals with large infarcts, non-infarcted areas of the left ventricle and right ventricle 
exhibit increased mRNA expression for pre-collagen type I and III [31], which may result in collagen accumulation progressive. Thus, large infarctions often accompany different degrees of fibrosis in noninfarcted areas $[8,32]$. The event of hyalinization analyzed in the right ventricle by anatomopathological evaluation in our study observed in $9 \%$ of the mice of the IM + PBS group and in none of the animals in the Control group.

Finally, pulmonary alterations in anatomopathological analysis demonstrated in our study, due to the surgical manipulation. This observation concluded from the results concerning the congestion and inflammatory infiltrate in the animals that underwent the surgical procedure in which the left coronary artery was not obstructed (Control group). In spite of the care related to the mobilization of the animal throughout the procedure, the experimental model itself is extremely invasive for the animal and even without the obstruction of the artery and induction of the infarction, a high inflammatory process and fibrosis production occurs in the attempt of tissue repair. However, our results allow us to conclude that the infarct model resulting from left coronary artery ligation is a good experimental model of infarction induction.

\section{References}

1. Hasenfuss G (1998) Animal models of human cardiovascular disease, heart failure and hypertrophy. Cardiovasc Res 39: 60-76. [Crossref]

2. Tucci P (2011) Pathophysiological characteristics of the post-myocardial infarction heart failure model in rats. Arquivos Brasileiros de Cardiologia 96: 420-424.

3. Heimburger RF (1946) Injection into pericardial sac and ligation of coronary artery of the rat. Arch Surg 52: 677-689. [Crossref]

4. Johns TN, Olson BJ (1954) Experimental myocardial infarction. I. A method of coronary occlusion in small animals. Ann Surg 140: 675-682. [Crossref]

5. Lutz M, Rosenberg M, Kiessling F, Eckstein V, Heger T, et al. (2008) Local injection of stem cell factor (SCF) improves myocardial homing of systemically delivered c-kit + bone marrow-derived stem cells. Cardiovasc Res 77: 143-150. [Crossref]

6. Frangogiannis NG (2008) The immune system and cardiac repair. Pharmacol Res 58: 88-111. [Crossref]

7. Chorro FJ, Such-Belenguer L, López-Merino V (2009) Modelos animales de enfermedad cardiovascular. Revista Espnhola de Cardiologia 62: 69-84.

8. Zornoff L, Paiva S, Minicucci M, Spadaro J (2009) Experimental myocardium infarction in rats: analysis of the model. Arquivos Brasileiros de Cardiologia 93: 434-440.

9. Lutgens E, Daemen MJ, de Muinck ED, Debets J, Leenders P, et al. (1999) Chronic myocardial infarction in the mouse: cardiac structural and functional changes. Cardiovasc Res 41: 586-593. [Crossref]

10. Manikandan P, Sumitra M, Nayeem M, Manohar BM, Lokanadam B, et al. (2004) Time course studies on the functional evaluation of experimental chronic myocardial infarction in rats. Mol Cell Biochem 267: 47-58. [Crossref]

11. de Leon EB, Bortoluzzi A, Rucatti A, Nunes RB, Saur L, et al. (2011) Neuromuscular electrical stimulation improves GLUT-4 and morphological characteristics of skeletal muscle in rats with heart failure. Acta Physiol (Oxf) 201: 265-273. [Crossref]

12. Francis J, Weiss RM, Wei SG, Johnson AK, Felder RB (2001) Progression of heart failure after myocardial infarction in the rat. Am J Physiol Regul Integr Comp Physiol 281: R1734-1745. [Crossref]
13. Phan TT, Shivu GN, Abozguia K, Sanderson JE, Frenneaux M. (2012) The pathophysiology of heart failure with preserved ejection fraction: from molecular mechanisms to exercise haemodynamics. Int J Cardiol. 26;158: 337-343. [Crossref]

14. Thomas DP, Hudlická O (1999) Arteriolar reactivity and capillarization in chronically stimulated rat limb skeletal muscle post-MI. J Appl Physiol (1985) 87: 2259-2265. [Crossref]

15. Rehn TA, Borge BA, Lunde PK, Munkvik M, Sneve ML, et al. (2009) Temporary fatigue and altered extracellular matrix in skeletal muscle during progression of heart failure in rats. Am J Physiol Regul Integr Comp Physiol 297: R26-33. [Crossref]

16. Jennings RB, Reimer KA (1991) The cell biology of acute myocardial ischemia. Annu Rev Med 42: 225-246. [Crossref]

17. Ferreira JC, Rolim NP, Bartholomeu JB, Gobatto CA, Kokubun E, et al. (2007) Maximal lactate steady state in running mice: effect of exercise training. Clin Exp Pharmacol Physiol 34:760-765.

18. Farahmand P, Lai TY, Weisel RD, Fazel S, Yau T, et al. (2008) Skeletal myoblasts preserve remote matrix architecture and global function when implanted early or late after coronary ligation into infarcted or remote myocardium. Circulation 118: S130137. [Crossref]

19. Payne TR, Oshima H, Okada M, Momoi N, Tobita K, et al. (2007) A relationship between vascular endothelial growth factor, angiogenesis, and cardiac repair after muscle stem cell transplantation into ischemic hearts. J Am Coll Cardiol. 23;50: 167784. [Crossref]

20. Vanzelli AS. Efeitos da associação entre treinamento físico e tratamento farmacológico com Beta-bloqueadores sobre a cardiomiopatia induzida por hiperatividade simpática em camundongos. São Paulo: Universidade de São Paulo; 2009.

21. Fischer AH, Jacobson KA, Rose J, Zeller R (2008) Hematoxylin and eosin staining of tissue and cell sections. CSH Protoc 2008: pdb. [Crossref]

22. Wick M, editor. Diagnostic Histochemistry. 1 ed. New York: Cambridge University; 2008

23. Ferreira JC, Boer BN, Grinberg M, Brum PC, Mochly-Rosen D. (2012) Protein quality control disruption by PKCbetaII in heart failure; rescue by the selective PKCbetaII inhibitor, betaIIV5-3. PLoS One. 7: e33175.

24. Lopes RD, Batista Júnior ML, Rosa JC, Lira FSd, Martins Jr E, et al. (2010) Changes in the production of IL-10 and TNF-a in skeletal muscle of rats with heart failure secondary to acute myocardial infarction. Arquivos Brasileiros de Cardiologia 94: 313-320.

25. Pfeffer MA, Pfeffer JM, Fishbein MC, Fletcher PJ, Spadaro J, et al. (1979) Myocardial infarct size and ventricular function in rats. Circ Res 44: 503-512. [Crossref]

26. Bacurau AV, Jardim MA, Ferreira JC, Bechara LR, Bueno CR, et al. (2009) Sympathetic hyperactivity differentially affects skeletal muscle mass in developing heart failure: role of exercise training. J Appl Physiol.106: 1631-1640. [Crossref]

27. Pina IL, Apstein CS, Balady GJ, Belardinelli R, Chaitman BR, et al. (2003) Exercise and heart failure: A statement from the American Heart Association Committee on exercise, rehabilitation, and prevention. Circulation 4;107: 1210-1225.

28. Olivetti G, Capasso JM, Meggs LG, Sonnenblick EH, Anversa P (1991) Cellular basis of chronic ventricular remodeling after myocardial infarction in rats. Circ Res 68: 856869. [Crossref]

29. Ratliff NB, Hackel DB (1980) Combined right and left ventricular infarction pathogenesis and clinicopathologic correlations. Am J Cardiol 45: 217-221. [Crossref]

30. Goldman S1, Raya TE (1995) Rat infarct model of myocardial infarction and heart failure. J Card Fail 1: 169-177. [Crossref]

31. Ertl G, Frantz S (2005) Healing after myocardial infarction. Cardiovasc Res 66: 22-32. [Crossref]

32. Sun Y, Weber KT (2000) Infarct scar: a dynamic tissue. Cardiovasc Res 46: 250-256 [Crossref]

Copyright: (C2017 Brosina de Leon E. This is an open-access article distributed under the terms of the Creative Commons Attribution License, which permits unrestricted use, distribution, and reproduction in any medium, provided the original author and source are credited. 